7. Barr LC, Robinson MH, Fisher C, Fallowfield ME, Westbury G. Limb conservation for soft tissue sarcomas of the shoulder and pelvic girdles. Br J Surg 1989;76:1198-201.

8. Adrien D, Marcus L, Ammar K, etal. Proximal major limb amputations - A retrospective analysis of 45 oncological cases World Jornal of Surgical oncologyn 2009, 7:15doi:10.1186/1477-7819-7-15

9. Wittig JC, Bickels J, Kollender Y, Kellar-Graney KL, Meller I, Malawer MM. Palliative forequarter amputation for metastatic carcinoma to the shoulder girdle region: Indications, preoperative evaluation, surgical technique, and results. J Surg Oncol. 2001;77:105-14.

10. Yoak MB, Cocke WM, Jr, Carey JP. Interscapulothoracic amputation. W V Med J. 2001;97:148-50

11. Merimsky $\mathrm{O}^{\mathrm{a}}$, Kollender $\mathrm{Y}^{\mathrm{b}}$, Inbar $\mathrm{M}^{\mathrm{a}}$, etal. Is Forequarter Amputation Justified for Palliation of Intractable Cancer Symptoms? International jornal for cance research and treatment Vol. 60, no 1. 2001 ( Oncology 2001;60:55-59)

12. Malawer MM, Buch RG, Thompson WE, Sugarbaker PH. Major amputations done palliative intent in the treatment of local bony complications associated with advanced cancer. $J$ Surg Oncol 1991; 47:121-30.

13. Rickelt. J, Hoekstra. H, van Coevorden. $\mathrm{F}$ et al. Forequarter amputation for malignancy. Br J Surg July $2009 ; 96: 7$ : 792-798

14. Murray C, Lopez A. The global burden of disease., Vol 1 Cambridge, MA: Harvard University Press, 1996.

15. Museru LM, Mcharo CN, Leshabari MT Road Traffic Accidents in Tanzania: A Ten Years Epidemiological Appraisal. East African Journal of Surgery: 2002; vol 7(1) :23-26

16. Museru LM, Mboya JA. Dodoma Train disaster Shortcoming of emergency respond and lesson learned. Tanzania Medical Journal:2003 ; vol18(1):28-31

17. Adar R, Schramek A, Khodadadi J, et al: Arterial combat injuries of the upper extremity. $J$ Trauma 1980; 20:297.

18. Adinolfi MF, Hardin WD, O'Connell RC, et al: Amputations after vascular trauma in civilians. South Med J 1983; 76:1241.

\title{
Single-surgeon Extensile Approach and Fixation of Thoraco-lumbar Pathology: A Review of our Experience.
}

\section{N. S. Motsitsi M.MED}

University of Pretoria. Department of Orthopaedic Surgery, Kalafong hospital

Private Bag x 396 Pretoria - South Africa 0001.

E-mail: silas.motsitsi@up.ac.za

Background: Extensile approaches to the thoracic and lumbar spine are required for tumours, fractures, malignancies, deformity corrections and degenerative diseases. The body cavities (thorax and abdomen) require different approaches depending on the primary pathology and the desired exposure plus fixation method. There is usually two teams involved: the 'exposure surgeon' and the 'operating surgeon'. Such a team is usually not feasible in developing countries. The purpose of this paper is to find out whether it is safe for a single surgeon to do both the exposure and the operation.

Methods: Nineteen patients operated on by a single surgeon over a three-year period were reviewed. This is a retrospective study. The information was obtained from clinical records.

Results: There were 10 females and 9 males, all below the age of 60 years. Four cases were due to infection, 14 due to trauma and 1 due to metastasis. The approach was dictated to by the pathology. The approaches were thoracotomy in 5, trans-thoracic trans-diaphragmatic retroperitoneal in 5 and $12^{\text {th }}$ rib sub costal retroperitoneal in 9. 
There were 4 intra-operative and 1 post-operative significant complications. All were managed successfully.

Conclusion: An experienced spinal surgeon can safely do both the approach and operative intervention. The complications can be safely managed. There is no increase in the complication rate.

\section{Introduction}

Extensile exposures to the thoraco-lumbar spine is indicated in trauma, infection, degenerative disease, tumours and deformities. The type of exposure depends on the location of the pathology and the extend of the accessibility required. The approach may be transthoracic (thoracotomy), transthoracic-transdiaphragmatic and retroperitoneal (TTTDRP) or sub diaphragmatic retroperitoneal $\left(12^{\text {th }}\right.$ rib sub diaphragmatic RP).These are technically difficult and potentially dangerous approaches. The learning curve is also very steep.

In most developed countries, there is a team made up of 'exposure surgeons' and 'operating surgeons'. The former will generally be either general or vascular surgeons and the latter will either be spinal orthopaedic or neurosurgeons. The 'exposure surgeons' are considered suitable for this surgery because of their unique knowledge of the area and the retroperitoneal structures. ${ }^{1}$ There may also be a 'dedicated team' for such extensive operations. ${ }^{2}$ The availability of such a team is rare in developing countries. The number of patients who need such an expertise or service is very large. The available surgeon must simply be so versatile as to act as both the 'exposure' and 'operating' surgeon if he is to be of value to the community. This is a huge undertaking for a single surgeon. The purpose of this paper is to find out whether there is an increase in the complication rate when a single surgeon does both the exposure and the surgery. The surgical techniques and the approaches described are not novel. The author does not specifically focus on the outcome of the operative procedures per se.

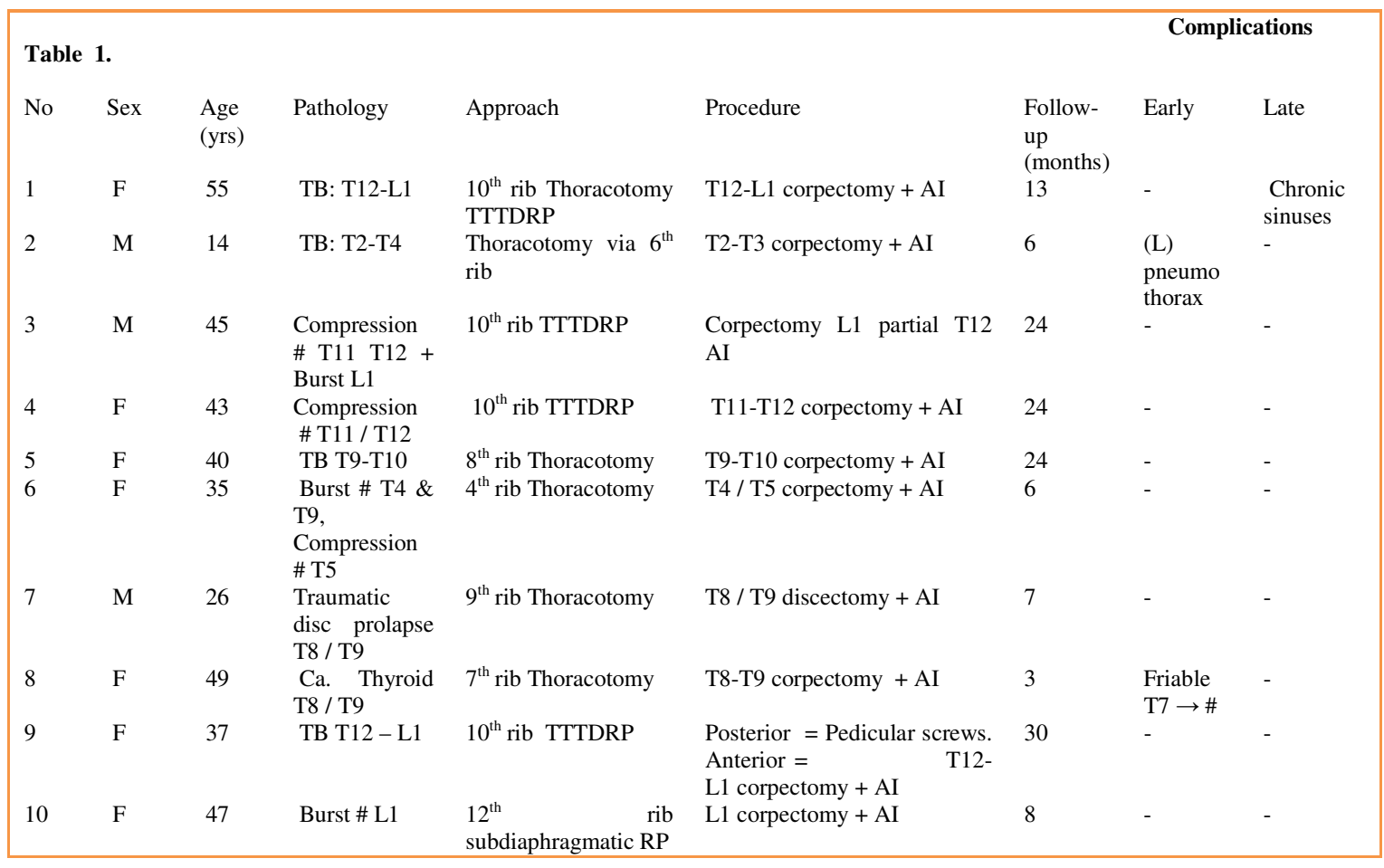




\begin{tabular}{|c|c|c|c|c|c|c|c|c|}
\hline 11 & M & 33 & Chance \# T12 & $10^{\text {th }}$ rib TTTDRP & $\mathrm{T} 12$ corpectomy $+\mathrm{AI}$ & 3 & - & - \\
\hline 12 & $\mathrm{~F}$ & 32 & $\begin{array}{l}\text { Compression } \\
\text { \# L1 }\end{array}$ & $\begin{array}{l}12^{\text {th }} \text { rib } \\
\text { subdiaphragmatic } \\
\text { RP }\end{array}$ & $\mathrm{L} 1$ corpectomy + AI & 24 & $\begin{array}{l}\text { Septic } \\
\text { bone- } \\
\text { graft } \\
\text { donor } \\
\text { area }\end{array}$ & - \\
\hline 13 & M & 36 & Burst \# L1 & $\begin{array}{lr}12^{\text {th }} & \text { rib } \\
\text { subdiaphragmatic } & R P\end{array}$ & $\mathrm{~L} 1$ corpectomy $+\mathrm{AI}$ & 3 & $\begin{array}{l}\text { Pneumot } \\
\text { horax }\end{array}$ & - \\
\hline 14 & $\mathrm{~F}$ & 17 & Burst \# L1 & $\begin{array}{l}12^{\text {th }} \\
\text { subdiaphragmatic RP }\end{array}$ & L1 corpectomy + AI & 1 & - & $? ?$ \\
\hline 15 & M & 32 & Burst \# L2 & $\begin{array}{ll}12^{\text {th }} & \text { rib } \\
\text { subdiaphragmatic } & \mathrm{RP}\end{array}$ & $\begin{array}{l}\text { Posterior = Pedicular screws } \\
\text { L1+L3. Anterior } \\
\text { corpectomy L2 }+ \text { AI }\end{array}$ & 14 & $\begin{array}{l}\text { Diaphra } \\
\text { gmatic } \\
\text { tears due } \\
\text { to } \\
\text { adhesion } \\
\text { s. } \\
\text { Pleural } \\
\text { tear }\end{array}$ & - \\
\hline 16 & $\mathrm{~F}$ & 40 & $\begin{array}{l}\text { Old \# - } \\
\text { dislocation: } \\
\text { Compression } \\
\text { \# L1 }\end{array}$ & $\begin{array}{ll}12^{\text {th }} & \text { rib } \\
\text { subdiaphragmatic } & \mathrm{RP}\end{array}$ & $\mathrm{L} 1$ corpectomy + AI & 3 & $=$ & $=$ \\
\hline 17 & M & 50 & $\begin{array}{l}\text { Compression } \\
\text { \# L1 }\end{array}$ & $\begin{array}{ll}12^{\text {th }} & \text { rib } \\
\text { subdiaphragmatic RP }\end{array}$ & $\mathrm{L} 1$ corpectomy + AI & 12 & $=$ & $=$ \\
\hline 18 & M & 39 & Burst \# L1 & $\begin{array}{l}12^{\text {th }} \quad \text { rib } \\
\text { subdiaphragmatic RP }\end{array}$ & $\mathrm{L} 1$ corpectomy $+\mathrm{AI}$ & 1 & $=$ & $=$ \\
\hline 19 & M & 24 & Burst \# L1 & $\begin{array}{l}12^{\text {th }} \text { rib } \\
\text { subdiaphragmatic RP }\end{array}$ & $\mathrm{L} 1$ corpectomy $+\mathrm{AI}$ & 21 & $=$ & $=$ \\
\hline
\end{tabular}

Abbreviations: \# = Fracture(s), TTTDRP = Trans thoracic trans-diaphragmatic and retroperitoneal, RP = Retroperitoneal and $\mathrm{AI}=$ Anterior instrumentation.

\section{Materials and Methods}

This retrospective study was undetaken at a secondary 800-beds hospital affiliated to the tertiary institution. Patients treated for thoraco-lumbar pathology from March 2006 up to June 2009 were all operated on by the author. The information was collected prospectively using a pro-forma. No IRB approval was needed for review of retrospective studies. The demographic data, primary pathology, surgical approach, type of operation and the complications are illustrated in the accompanying table.

\section{Results}

There were 19 patients with an average age of 37 years (range:14-55 years).

There were 10 females and 9 males. The pathology was: trauma $(n=14)$, infection $(n=4)$ and metastasis $(n=1)$. The position during surgery was right lateral decubitus ( in all) plus prone in those who needed additional transpedicular screw fixation. The approach was from the left side. Five patients needed thoracotomy (Figure 1), five TTTDRP and nine $12^{\text {th }}$ rib sub diaphragmatic RP. All cases had corpectomy plus anterior instrumentation. Patients 9 and 15 needed additional posterior transpedicular screw fixation. The former had simultaneous anterior and posterior procedure and the latter had a staged operation (figure 2). The average duration for the operation was 3.0 hours (range: 2.5 - 3.5 hours) for anterior procedures. The patient who needed anterior plus posterior procedure during the same anaesthesia took 5.5 hours. The average blood loss was 600 milliliters (ml) (range $300-900 \mathrm{ml}$ ). Patient 9 had the highest blood loss of $1500 \mathrm{ml}$. 
All patients were admitted to the high-care unit post-operatively. The average stay in high-care was about 4 days (range 3-5 days). There were no intra-operative or immediate post operative mortality. No patient needed revision surgery either because of technical complications or implant problems.

Significant complications were recorded in all cases. These are complications that either needed corrective actions during the operation or the complications affected the course of the final event. There were five significant complications: four were intra-operative ( 2 pneumothoraces, one diaphragmatic and pleural tears and one fracture of the vertebra during internal fixation) and one post-operative (sepsis of bone-graft donor area). All were managed successful. The follow-up was, on average, 11 months (range 1 - 30 months).

\section{Discussion}

A single surgeon can safely do both the extensile exposure and operative intervention. The complication rate is fairly low and is not higher than those reported in the literature. The types of complications, though significant, were fairly easy to handle and did not affect the final outcome. It should always be borne in mind that both the exposure and the operation are technically very demanding and dangerous.

Very few spinal surgeons perform these spinal procedures independently. ${ }^{3}$ Holt Richard et al. reviewed 450 patients done by a single spinal surgeon for deformity corrections, fractures, tumours, infections and degenerative disease of the spine. They concluded that the complication rate is lower ${ }^{3}$.

Thoraco-lumbar procedures have a high complication rate: may reach up to $31 \%$. Major complications may be up to $11 \%{ }^{4,5}$ Antero-lateral approach via the left side has a very low complication because all major structures are under direct vision. ${ }^{6}$ Up to $50 \%$ of patients who had thoracotomy experience pulmonary complications. ${ }^{7}$ Anterior and posterior procedures $\left(360^{\circ}\right.$ spinal operation) during the same anaesthesia carries a higher complication rate $^{8} \mathrm{~A}$ staged procedure in this case has a lower complication rate. Staged procedure is safe, has low blood loss and is reliable. ${ }^{9}$ The availability of two surgical team in such cases is an important factor in the success of the procedure. ${ }^{10}$ Such a team maximizes available surgical skills and therefore decreases the complication rate ${ }^{11}$.

The limitations of the study are: retrospective in nature, few patients and there is no comparative group.

\section{Conclusion}

A well-trained and experienced spinal surgeon can safely do the approach and surgery of the thoraco-lumbar pathology. The complication rate is acceptable.

\section{References}

1. Chiriano Jason D O, Abou-Zamzam Ahmed M. Jr, Urayeneza Olivier B S, Zhang Wayne $\mathrm{W}$, and Cheng Wayne. The role of the vascular surgeon in anterior retroperitoneal spine exposure: Preservation of open surgical training. Journal of Vascular Surgery. 50(1): 148 - 151, July 2009.

2. Luke Brewster, Nathan Trueger, Carol Schemer, Alex Ghanayem and John Santaniello. World J. Surg (2008) 32: 1414 - 1419. Infraumbilical Anterior Retroperitoneal Exposure of the Lumbar Spine in 128 Consecutive Patients. 
3. Holt Richard T., Majd Mohammad E., Vadhva Mukta and Castro Frank. The Efficacy of Anterior Spine Exposure by an Orthopedic Surgeon. Journal of Spinal Disorder and Techniques. Volume 16(5), October 2003, pp 477 - 486.

4. Dimar John R. III, Puno Rolando M, Johnson John R. Perioperative Complications of Anterior Procedures on the Spine. JBJS. Volume 78-A (6), June 1996, pp 839 - 847.

5. Knop C., Bastian L., Lange U., Oeser M., Zdichavsky M, Blauth M. Complications in surgical treatment of Thoracolumbar injuries. Eur Spine J ( 2002) 11: 214 - 226.

6. Inamasu J, Guiot B. H. Vascular injury and complication in neurosurgical spine surgery. Acta Neurochir (Wien) (2006) 148: 375 - 387.

7. McAfee Paul C. Complications of Anterior Approaches to the Thoracolumbar Spine. Clinical Orthopedics and Related Research, Number 306, September, 1994. pp 110 119.

8. Snell Brian E., Nasr Fadi F., Wolfla. Single-stage Thoracolumbar vertebrectomy with circumferential reconstruction and arthrodesis: surgical technique and results in patients. Operative Neurosurgery 2, Volume 58: April 2006.

9. Payer M. Unstable burst fractures of the thoraco-lumbar junction: treatment by posterior bisegmental correction/fixation and staged anterior corpectomy and titanium cage implantation. Acta Neurochir (Wien) (2006) 148: 299 - 306.

10. Ozturk Cagatay, Aydinli Ufuk, Vural Recep, Sehirlioglu and Mutlu Muren. Simultaneous versus sequential one - stage combined anterior and posterior spinal surgery for spinal infections ( outcomes and complications)

11. Gumbs Andrew A., Bloom Norman D., Bitan Fabian D. and Hanan Scott H. Open anterior approaches for lumbar spine procedures. The American Journal of Surgery 194 (2007) 98 - 102. 